\title{
Biotinylated Microbubbles Targeted to Amyloid
}

\author{
Arlymae Rand ${ }^{1}$, Gregory Gilman ${ }^{2}$, Dennis J. O’Kane ${ }^{1}$ and Marek Belohlavek ${ }^{3, *}$ \\ ${ }^{1}$ Mayo Clinic, Rochester, Minnesota; ${ }^{2}$ Kardia Health Systems, Rochester, Minnesota and ${ }^{3}$ Mayo Clinic, Scottsdale, \\ Arizona, USA
}

\begin{abstract}
Background: Ultrasonography uses microbubbles for enhanced imaging. We created microbubbles that have preferential adherence to amyloid protein by utilizing the affinity of serum amyloid component P (SAP) to amyloid along with avidin-biotin interactions.

Methods: Biotin-labeled albumin was incorporated into the albumin shell of fluorocarbon gas-filled bubbles. The bubble was attached through a bridge with biotin incorporated into the shell of the bubble and incubated with avidin-labeled SAP which was pre-bound to SA ("synthetic amyloid"). This resulted in a bubble targeted to amyloid. The bubbles were evaluated using fluorescent microscopy and fluorescence-activated cell sorting (FACS).

Results: Microbubbles with a protein shell were bound to amyloid by utilizing the affinity of SAP for amyloid and biotinavidin interactions.

Conclusion: We introduce microbubbles specifically targeted to amyloid deposits and intended as future mediators of ultrasound detection of amyloid deposits and amyloid-selective drug delivery.
\end{abstract}

Key Words: Targeted microbubbles, amyloid.

\section{INTRODUCTION}

Ultrasound imaging utilizes microbubbles clinically as blood tracers [1] and experimentally for visualization of specific tissue targets [2]. One target that has not been explored is amyloid. Amyloid deposits form in primary amyloidosis and their presence in the brain is diagnostic of Alzheimer's disease [3]. Microbubbles can cross the blood-brain barrier [4] and could in time contribute to diagnosis and drug delivery in Alzheimer's disease [5]. The goal of this study was to utilize the affinity of serum amyloid component P(SAP) to amyloid $[6,7]$ and create microbubbles that would recognize amyloid as a target structure. Coupling this interaction with avidin and biotin interactions, a complex was created consisting of a microbubble bound to amyloid by the interaction of SAP to amyloid. Development and in vitro testing of amyloid-targeted bubbles is reported here.

\section{MATERIAL AND METHODOLOGY}

Biotin-labeled albumin was synthesized using Plasbu$\min { }^{\circledR}-25$ (Bayer, Elkhart, IN), a 25\% human albumin solution (HuSA) after dialysis using the FluoReporter ${ }^{\circledR}$ BiotinXX Protein Labeling kit from Molecular Probes, Eugene, OR. Biotin-XX succinimidyl ester in dimethyl sulfoxide at $20 \mathrm{mg} / \mathrm{ml}$ was added to $100 \mathrm{mg}$ albumin in $0.1 \mathrm{M}$ sodium bicarbonate to achieve a ratio of 10 molecules of biotin-ester per molecule of protein. The components were stirred for one hour and purified using size exclusion filtration. Biotinlabeled bubbles were prepared after the general method

*Address correspondence to this author at the Mayo Clinic Arizona, Johnson Research Building 3-361, 13400 E. Shea Boulevard, Scottsdale, Arizona 85259, USA; Tel: 480-301-6694 (office), 480-301-6870 (admin. assistant); Fax: 480-301-9162; E-mail: belohlavek.marek@mayo.edu described by Porter [8] by mixing 1 part biotin-labeled HuSA with 3 parts unlabeled HuSA and 4 parts 5\% dextrose in water, then loaded with 4 parts tetrafluorobutane gas, and sonicated for 30 seconds using a Misonix Sonicator (Ultrasonic Processor XL, Farmingdale, NY).

SAP was purified from previously frozen plasma after addition of $\mathrm{CaCl} 2$ to a concentration of $10 \mathrm{mM}$, incubated overnight at $4^{\circ} \mathrm{C}$ and filtered $[9,10]$. DNA-conjugated agarose (Amersham, Piscataway, NJ) was prewashed in $10 \mathrm{mM}$ Tris- $\mathrm{HCl}$ (pH 7.4), $1 \mathrm{M} \mathrm{NaCl}$, and $25 \mathrm{mM} \mathrm{CaCl}$. The agarose was washed three additional times in TN2 $(10 \mathrm{mM}$ Tris$\mathrm{HCl}(\mathrm{pH} 7.4), 150 \mathrm{mM} \mathrm{NaCl}$, and $2 \mathrm{mM} \mathrm{CaCl} 2$ ), and then mixed with filtered plasma for 1 hour at room temperature. The slurry was transferred to a chromatography column, washed with TN2 until absorption of the eluate at $280 \mathrm{~nm}$ returned to background level and SAP eluted with $10 \mathrm{mM}$ Tris- $\mathrm{HCl}$ at $\mathrm{pH} 7.4,150 \mathrm{mM} \mathrm{NaCl}$, and $10 \mathrm{mM}$ EDTA. The final preparation was stored in TNA $(10 \mathrm{mM}$ Tris- $\mathrm{HCl}(\mathrm{pH}$ 7.4) and $100 \mathrm{mM} \mathrm{NaCl}$ ). Preparations when electrophoresed on native and denaturing polyacrylamide gel electrophoresis migrated similarly with commercially available material (data not shown). Labeling the SAP with avidin was accomplished using maleimide-activated NeutrAvidin and N-succinimidyl S-acetylthiopropionate chemistry as per manufacturer's suggested protocols (Pierce Chemical Co, Rockford, IL).

To prepare synthetic amyloid (SA), one hundred micrograms of amyloid $\beta$ peptide residues 1-42 (Sigma Chemical Co., St Louis, MO) was dissolved in $15 \mu 1$ of dimethyl sulfoxide [11]. The peptide solution was diluted to $300 \mu \mathrm{l}$ in TNA and stirred for 5 hours at $37^{\circ} \mathrm{C}$ [11]. To label SA with Alexa488, 200 $\mu \mathrm{g}$ of dialyzed SA was labeled with the Invi- 
trogen Corporation (Carlsbad, CA) kit. This preparation and all other reagents were stored in TN buffer at $4^{\circ} \mathrm{C}$.

To bind the SAP to the synthetic amyloid, $5 \mu$ of the labeled SA or labeled amyloid fibrils (AF) preparation was added to $50 \mu 1$ of avidin-SAP. In some instances, the mixture was adjusted to contain the desired concentration of $\mathrm{CaCl} 2$. After $1 \mathrm{hr}$ stirring at $37^{\circ} \mathrm{C}$, the mixture was slowly cooled to room temperature overnight. To evaluate the resulting preparations, fresh microbubbles were mixed gently and added to the synthetic amyloid plus SAP, and evaluated using FACS (Becton Dickinson FACS Calibur) as previously demonstrated $[12,13]$. As soon as possible after FACS, the microbubbles were examined using a Zeiss phase fluorescence microscope and photographed using an AxioPhot digital camera.

\section{RESULTS}

Targeted bubble assembly was documented by FACS and fluorescent microscopy. Fig. (1A) documents the lack of fluorescence seen in the bubble preparation alone. The rings around the bubbles are due to the spherical shape of the bubble. The distribution of forward scatter versus green fluorescence shown in Fig. (1A) defined the R1 region (i.e., background; with the presence of the negative bubbles exhibiting no fluorescence) while in Fig. (1B) the R2 (i.e., positive fluorescence) was established with a highly fluorescent sample.
To validate the area designated positive, we mixed the biotin-labeled albumin bubbles with commercial fluorescein isothiocyanate conjugated avidin, which can be analyzed using the same filters used for Alexa488. These bubbles showed a high degree of fluorescence with $>90 \%$ registering as positive.

Fig. (1C) illustrates the decoration of the SAP labeled with avidin by a commercially obtained fluorescent biotin. FACS showed intensity counts within the fluorescence response field for a wide range of sizes. A predominantly nonspherical appearance was seen in fluorescence microscopy.

The FACS histogram of Fig. (1D), i.e., the targetedbubble, shows intense fluorescence in the $\mathrm{R} 2$ field due to biotinylated bubbles. There is an interesting highly reproducible pattern in which the size distribution resembled quanta rather than a continuum, possibly corresponding to an interference of fluorescence intensities at points of bubble to bubble contact as seen upon visual examination of the microbubbles on the fluorescent microscope.

Table 1 summarizes percent positive counts by FACS for different formulations of microbubble constructs from repeated experiments. Plain or biotinylated microbubble formations without an attached complex produced background count. When fluorescent synthetic amyloid or fluorescent amyloid fibrils and avidin-labeled SAP were added to the

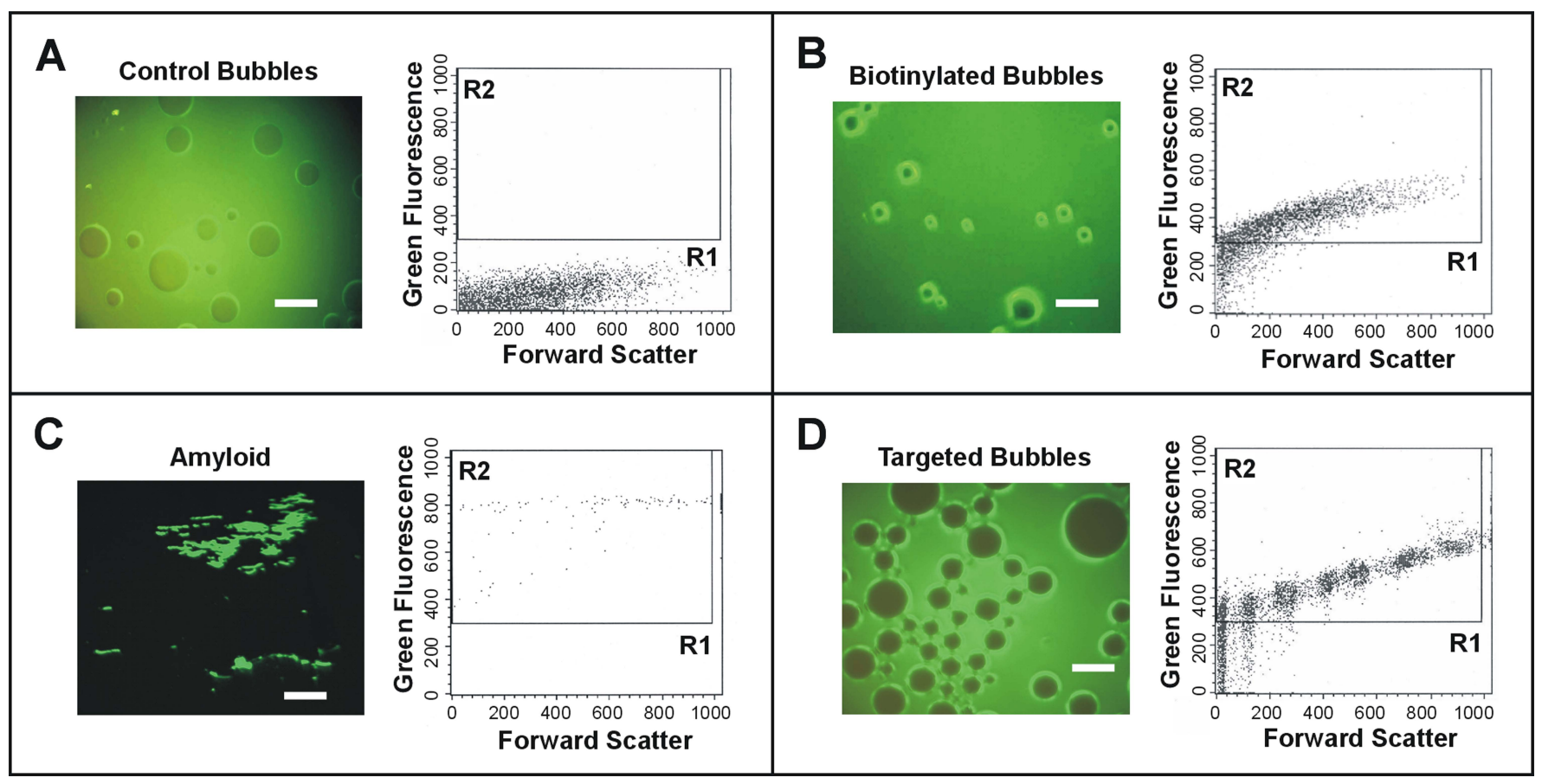

Fig. (1). Microscopic and FACS analyses of stages in creation of amyloid-targeted microbubbles. Each panel is composed of a representative image seen using the fluorescent microscope and the FACS data expressed as a plot with forward scatter versus green fluorescence. A, Control microbubbles expectably characterized by a lack of fluorescence and accumulation of scatter in the R1 region which was defined by examining bubbles alone with no fluorescent moieties added. B. The high degree of fluorescence seen on the surface of the bubbles was generated by adding a green fluorescent labeled avidin (Pierce Chemical Co., Rockford, IL) to the biotin-labeled bubble and shows the expected distribution of values in the R2 (positive) range of the plot. This is confirmed by examination of the material microscopically. C, Binding of the avidin-labeled SA to a commercial green fluorescent-labeled biotin instead of a bubble. The microscope showed the decorated SA material illuminated with green fluorescence and the histogram demonstrates the absence of the material seen when testing materials containing bubbles. D, FACS analysis showing density characteristic for bubbles and distribution (in the 'R2' or positive field) characteristic for fluorescence. Microscopy shows highly fluorescent microbubbles. The bar indicates 100 microns. 
mix of biotinylated microbubbles, high percentage counts were repeatedly produced. Amyloid fibrils extracted from liver tissue (courtesy of Dr. Roshini Abraham, Mayo Clinic) were used in place of the SA and demonstrated the binding parameters as seen with the synthetic amyloid.

Some studies suggest that calcium may facilitate the binding of amyloid to SAP [14-17]. As iterations with various concentrations of calcium in Table $\mathbf{1}$ demonstrate, calcium had no apparent effect on the binding in our in vitro system. As a further confirmation of the independence of this association with calcium, introduction of $50 \mathrm{mM}$ EDTA had no appreciable effect on the targeted bubble construct.

\section{DISCUSSION AND CONCLUSION}

We demonstrate a reproducible experimental methodology of targeting biotinylated albumin microbubbles to amyloid paving the way for targeted contrast-enhanced ultrasound imaging and possibly drug delivery in systemic amyloidosis and Alzheimer's disease. Extensive research involving contrast echocardiography and development of targeted bubbles exists [1, 2, 18], and initial experimental studies suggest feasibility of transcranial application of contrast echocardiography $[19,20]$. Our approach expands the field by utilizing SAP as a part of the SAP-avidin coupling complex thereby targeting the microbubbles to amyloid.

The methodology involved creation of microbubbles from human serum albumin [8] with tracer amounts of biotin, which were targeted to amyloid through the affinity of SAP. Our system enabled visible imaging by also incorporating avidin-biotin interactions along with fluorescent com- pounds for easy detection of molecules. While nonspecific binding of SAP to other proteins needs to be considered, SAP is a naturally occurring component and radiolabeled SAP has been shown to bind specifically to amyloid in vivo $[21,22]$.

Addition of calcium (0-4 mM levels existing in blood circulation) and/or EDTA $(50 \mathrm{mM})$ to the reaction yielded no change to the binding properties of the targeted bubbles, although calcium and EDTA were essential to the purification of synthetic amyloid [7, 23].

Our experimental protocol contained only portions of the components needed to form amyloid deposits in vivo. Assembly of amyloid in vivo requires not only the major protein component and SAP but also calcium and heparin sulfate and/or chondroitin sulfate proteoglycans, laminin, entactin, collagen IV, and apoE [24]. Our targeting system contained synthetic amyloid, SAP, and calcium without any of the additional components listed above.

While our bubbles were larger than those used in imaging, their size enabled examination of the amyloid-targetedbubbles using FACS and fluorescent microscopy. Smaller bubbles could be obtained by different bubble preparation techniques, size-filtering, or using commercial microbubbles with a defined diameter range and their shell made of HuSA (such as Optison ${ }^{\mathrm{TM}}$, GE Healthcare).

In conclusion, we describe a reproducible and specific method of construction of microbubbles targeted to amyloid in vitro, capitalizing on the well-established affinity of SAP to amyloid and using avidin-biotin interactions to facilitate

Table 1. Percent Counts by FACS of Various Microbubble Constructs

\begin{tabular}{|c|c|c|c|c|c|c|c|c|c|}
\hline \multirow{2}{*}{ Microbubbles } & \multirow{2}{*}{ SA } & \multirow{2}{*}{$\mathbf{A F}$} & \multirow{2}{*}{ Avi-SAP } & \multirow{2}{*}{ Calcium } & \multirow{2}{*}{ EDTA } & \multicolumn{2}{|c|}{ Experiment 1} & \multicolumn{2}{|c|}{ Experiment 2} \\
\hline & & & & & & Batch 1 & Batch 2 & Batch 1 & Batch 2 \\
\hline Plain & - & - & - & - & - & $3 \%$ & ND & 0 & 0 \\
\hline \multirow{12}{*}{ Biotinylated } & - & - & - & - & - & $0 \%$ & ND & 0 & 0 \\
\hline & + & - & + & $0.25 \mathrm{mM}$ & - & $96 \%$ & ND & ND & ND \\
\hline & + & - & + & $0.5 \mathrm{mM}$ & - & $98 \%$ & $95 \%$ & ND & ND \\
\hline & + & - & + & $0.75 \mathrm{mM}$ & - & $97 \%$ & $98 \%$ & ND & ND \\
\hline & + & - & + & $1.00 \mathrm{mM}$ & - & $98 \%$ & $97 \%$ & ND & ND \\
\hline & + & - & + & $2.00 \mathrm{mM}$ & - & $94 \%$ & $96 \%$ & ND & ND \\
\hline & + & - & + & $4.00 \mathrm{mM}$ & - & $97 \%$ & $97 \%$ & $93 \%$ & $93 \%$ \\
\hline & + & - & + & - & - & $95 \%$ & $95 \%$ & $95 \%$ & $89 \%$ \\
\hline & + & - & + & $4.00 \mathrm{mM}$ & $50 \mathrm{mM}$ & $97 \%$ & $97 \%$ & $95 \%$ & $93 \%$ \\
\hline & - & + & + & $4.00 \mathrm{mM}$ & - & $97 \%$ & $96 \%$ & $95 \%$ & $95 \%$ \\
\hline & - & + & + & - & - & $96 \%$ & ND & $95 \%$ & $95 \%$ \\
\hline & - & + & + & $4.00 \mathrm{mM}$ & $50 \mathrm{mM}$ & $96 \%$ & ND & $95 \%$ & $95 \%$ \\
\hline
\end{tabular}

Percentages are based on counts of 10,000 evaluated particles; 2 batches of microbubbles were tested in each experimental setting by the fluorescence-activated cell sorter (FACS). SA, synthetic amyloid; AF, fluorescent amyloid fibrils; Avi-SAP, avidin-labeled serum amyloid component P; ND, not done. Positive (+) and negative (-) signs denotes the presence or absence of the component. 
visualization of the complex. The binding compound thus utilizes physiological protein-protein interactions (rather than antigen-antibody interactions). Our development represents a prerequisite targeting system designed for future visualization of amyloid deposits by contrast-enhanced ultrasound and delivery of amyloid-targeted therapy.

\section{ACKNOWLEDGEMENTS}

We thank Danielle R. Wright for secretarial help. This study was supported by an NIH Grant HL68573 to Dr. Marek Belohlavek.

\section{REFERENCES}

[1] Kaufmann, B.A.; Wei, K.; Lindner, J.R. Contrast echocardiography. Curr. Probl. Cardiol., 2007, 32, 51-96.

[2] Lankford, M.; Behm, C.Z.; Yeh, J.; Klibanov, A.L.; Robinson, P.; Lindner, J.R. Effect of microbubble ligation to cells on ultrasound signal enhancement: implications for targeted imaging. Invest. Radiol., 2006, 41, 721-728.

[3] Morgan, D. Immunotherapy for Alzheimer's disease. J. Alzheimers Dis., 2006, 9, 425-432.

[4] Hynynen, K.; McDannold, N.; Vykhodtseva, N.; Jolesz, F.A. Noninvasive opening of BBB by focused ultrasound. Acta Neurochir. Suppl., 2003, 86, 555-558.

[5] Jong, A.; Huang, S.H. Blood-brain barrier drug discovery for central nervous system infections. Curr. Drug Targets Infect. Disord., 2005, 5, 65-72.

[6] Li, X.A.; Hatanaka, K.; Guo, L.; Kitamura, Y.; Yamamoto, A. Binding of serum amyloid $\mathrm{P}$ component to heparin in human serum. Biochim. Biophys. Acta, 1994, 1201, 143-148.

[7] Pepys, M.B.; Rademacher, T.W.; Amatayakul-Chantler, S.; Williams, P.; Noble, G.E.; Hutchinson, W.L.; Hawkins, P.N.; Nelson, S.R.; Gallimore, J.R.; Herbert, J.; Hutton, T.; Dwek, R.A. Human serum amyloid $\mathrm{P}$ component is an invariant constituent of amyloid deposits and has a uniquely homogeneous glycostructure. Proc. Natl. Acad. Sci. USA, 1994, 91, 5602-5606.

[8] Porter, T.R.; Xie, F. Visually discernible myocardial echocardiographic contrast after intravenous injection of sonicated dextrose albumin microbubbles containing high molecular weight, less soluble gases. J. Am. Coll. Cardiol., 1995, 25, 509-515.

[9] Pepys, M.B.; Butler, P.J. Serum amyloid P component is the major calcium-dependent specific DNA binding protein of the serum. Biochem. Biophys. Res. Commun., 1987, 148, 308-313.

[10] Hamazaki, H. Ca2+-mediated association of human serum amyloid P component with heparan sulfate and dermatan sulfate. J. Biol. Chem., 1987, 262, 1456-1460.

[11] Kudva, Y.C.; Hiddinga, H.J.; Butler, P.C.; Mueske, C.S.; Eberhardt, N.L. Small heat shock proteins inhibit in vitro A beta(142) amyloidogenesis. FEBS Lett., 1997, 416, 117-121.
[12] Joseph, S.; Olbrich, C.; Kirsch, J.; Hasbach, M.; Briel, A.; Schirner, M. A real-time in vitro assay for studying functional characteristics of target-specific ultrasound contrast agents. Pharm. Res., 2004, 21, 920-926.

[13] Christiansen, J.P.; French, B.A.; Klibanov, A.L.; Kaul, S.; Lindner, J.R. Targeted tissue transfection with ultrasound destruction of plasmid-bearing cationic microbubbles. Ultrasound Med. Biol., 2003, 29, 1759-1767.

[14] Nielsen, E.H.; Sorensen, I.J.; Vilsgaard, K.; Andersen, O.; Svehag, S.E. Calcium-enhanced aggregation of serum amyloid $\mathrm{P}$ component and its inhibition by the ligands heparin and heparan sulphate. An electron microscopic and immunoelectrophoretic study. APMIS, 1994, 102, 420-426.

[15] Danielsen, B.; Sorensen, I.J.; Nybo, M.; Nielsen, E.H.; Kaplan, B. Svehag, S.E. Calcium-dependent and -independent binding of the pentraxin serum amyloid $\mathrm{P}$ component to glycosaminoglycans and amyloid proteins: enhanced binding at slightly acid pH. Biochim. Biophys. Acta, 1997, 1339, 73-78.

[16] Baltz, M.L.; De Beer, F.C.; Feinstein, A.; Pepys, M.B. Calciumdependent aggregation of human serum amyloid $\mathrm{P}$ component Biochim. Biophys. Acta, 1982, 701, 229-236.

[17] Pepys, M.B.; Dyck, R.F.; de Beer, F.C.; Skinner, M.; Cohen, A.S. Binding of serum amyloid P-component (SAP) by amyloid fibrils. Clin. Exp. Immunol., 1979, 38, 284-293

[18] Villanueva, F.S.; Wagner, W.R.; Vannan, M.A.; Narula, J. Targeted ultrasound imaging using microbubbles. Cardiol. Clin., 2004 22, 283-298.

[19] Porter, T.R.; Kricsfeld, D.; Lof, J.; Everbach, E.C.; Xie, F. Effectiveness of transcranial and transthoracic ultrasound and microbubbles in dissolving intravascular thrombi. J. Ultrasound Med., 2001 20, 1313-1325.

[20] Xie, F.; Boska, M.D.; Lof, J.; Uberti, M.G.; Tsutsui, J.M.; Porter, T.R. Effects of Transcranial Ultrasound and Intravenous Microbubbles on Blood Brain Barrier Permeability in a Large Animal Model. Ultrasound Med. Biol., 2008.

[21] Hachulla, E.; Maulin, L.; Deveaux, M.; Facon, T.; Bletry, O.; Vanhille, P.; Wechsler, B.; Godeau, P.; Levesque, H.; Hatron, P.Y.; Huglo, D.; Devulder, B.; Marchandise, X. Prospective and serial study of primary amyloidosis with serum amyloid $\mathrm{P}$ component scintigraphy: from diagnosis to prognosis. Am. J. Med., 1996, 101 , 77-87.

[22] Hawkins, P.N. Serum amyloid P component scintigraphy for diagnosis and monitoring amyloidosis. Curr. Opin. Nephrol. Hypertens., 2002, 11, 649-655.

[23] Hawkins, P.N.; Wootton, R.; Pepys, M.B. Metabolic studies of radioiodinated serum amyloid $\mathrm{P}$ component in normal subjects and patients with systemic amyloidosis. J. Clin. Invest., 1990, 86, 18621869.

[24] Kisilevsky, R. Review: amyloidogenesis-unquestioned answers and unanswered questions. J. Struct. Biol., 2000, 130, 99-108.

(C) Rand et al.; Licensee Bentham Open.

This is an open access article licensed under the terms of the Creative Commons Attribution Non-Commercial License (http://creativecommons.org/licenses/ by-nc/3.0/) which permits unrestricted, non-commercial use, distribution and reproduction in any medium, provided the work is properly cited. 